\title{
Awareness, knowledge, attitude and practice of adverse drug reaction reporting among health workers and patients in selected primary healthcare centres in Ibadan, southwestern Nigeria
}

\author{
Rasaq Adisa* and Tomilayo I. Omitogun
}

\begin{abstract}
Background: Higher incidence of adverse drug reactions (ADRs) is a global health problem requiring attention of all stakeholders regardless of the practice settings. This study therefore aimed to evaluate awareness, knowledge, attitude and practice of ADR reporting among health workers and patients in 10 primary healthcare centres (PHCs) in Ibadan, southwestern Nigeria.

Methods: Questionnaire-guided cross-sectional survey among 80 health workers and 360 patients enrolled from the selected PHCs between October and December 2018. The semi-structured questionnaires generally comprised open-ended and closed-ended questions to explore general knowledge and awareness of ADRs and pharmacovigilance, while other question-items evaluated attitude towards ADR reporting and ADR reporting practice. Overall percent score in the knowledge and attitude domains for the health workers was developed into binary categories of $>80$ versus $\leq 80 \%$ for "adequate" and "inadequate" knowledge, as well as "positive" and "negative" attitude, respectively. Data were summarised using descriptive statistics, while Chi-square test was used to evaluate categorical variables at $p<0.05$.

Results: Overall, 58(72.5\%) health workers had heard of pharmacovigilance, but only 3(5.2\%) correctly understood the pharmacovigilance concept. Twelve (15.0\%) showed adequate knowledge of ADRs, while 37(46.2\%) demonstrated positive attitude towards ADR reporting. Thirty (37.5\%) health workers had come across ADR reporting form, while 79(98.8\%) expressed willingness to report all ADRs encountered. Of the patients, 31(8.6\%) had heard of pharmacovigilance, 143(39.7\%) correctly cited ADR definition, while 67(18.6\%) reported the previously experienced ADRs. Informing healthcare professional $(38 ; 38.8 \%)$ was the most common measure taken by patients when they experienced reaction(s). Nurses significantly had adequate knowledge of ADRs $(p<0.001)$ compared to other cadres.

\footnotetext{
*Correspondence: adisaras73@yahoo.co.uk; rasaq.adisa@mail.ui.edu.ng Department of Clinical Pharmacy and Pharmacy Administration, Faculty of Pharmacy, University of Ibadan, Ibadan, Nigeria
}

(c) The Author(s). 2019 Open Access This article is distributed under the terms of the Creative Commons Attribution 4.0 International License (http://creativecommons.org/licenses/by/4.0/), which permits unrestricted use, distribution, and reproduction in any medium, provided you give appropriate credit to the original author(s) and the source, provide a link to the Creative Commons license, and indicate if changes were made. The Creative Commons Public Domain Dedication waiver (http://creativecommons.org/publicdomain/zero/1.0/) applies to the data made available in this article, unless otherwise stated. 


\begin{abstract}
(Continued from previous page)
Conclusions: Health workers in the selected PHCs were largely aware of pharmacovigilance but show low level of knowledge about ADRs and pharmacovigilance concept, with moderately positive attitude towards ADR reporting. Patients on the other hand demonstrate low level of awareness of pharmacovigilance and ADR reporting, with less than one-fifth who reported the previously experienced ADRs. This perhaps underscores a need for regular mandatory education and training on ADRs/pharmacovigilance concept among the PHC health workers, while continuous public enlightenment and awareness campaign on spontaneous reporting of ADRs is advocated in order to enhance reporting rate.
\end{abstract}

Keywords: Adverse drug reaction reporting, Awareness, knowledge, attitude, and practice, Primary healthcare worker, Patients

\section{Background}

Higher incidence of adverse drug reactions (ADRs) is a global health problem requiring attention of all stakeholders regardless of the practice settings [1,2]. Adverse drug reactions have been reported as a significant cause of morbidity and mortality across all age groups, with appreciable number of hospital admissions, as well as substantial financial burden on the society and the healthcare systems $[2,3]$. Spontaneous ADR reporting system is a global phenomenon, and the cornerstone of pharmacovigilance activities [4]. Healthcare professionals in any capacity therefore play a crucial role in pharmacovigilance system, and as such they require considerable knowledge and expertise in the field of medication safety, especially for early recognition, detection, management and reporting of ADRs [5]. However, studies have indicated that a large proportion of ADRs are not reported by healthcare professionals, especially in developing countries [6-9] due to a number of factors including lack of awareness and knowledge of pharmacovigilance and ADR reporting $[5-7,10]$. It is estimated that only $6-10 \%$ of all ADRs are reported $[11,12]$. Thus, underreporting has been a major obstacle to spontaneous reporting of ADRs, and this poses a great challenge to pharmacovigilance activities $[4,7]$ as well as negatively impact public health $[7,13]$. Healthcare professionals are therefore expected to consider ADR reporting as their professional obligation, since an effective system of ADR reporting is important to improve patient care and safety [14] and in turn improving overall health [15, 16]. Similarly, patients play a vital role in spontaneous reporting system, as only the patient really feels the adverse effect of the drug [17]. The success or failure of any spontaneous reporting system depends on the active involvement of reporters [18]. Thus, direct patient participation in ADR reporting will increase efficiency of the pharmacovigilance system, as well as bridge the gap of underreporting on the part of healthcare professionals $[19,20]$.

Previous studies on pharmacovigilance and ADR reporting in Nigeria and many other developing countries $[6,8-10,14]$, focused mostly on healthcare practitioners in secondary and tertiary care settings with less attention paid to the primary healthcare centres (PHCs), which are the closest to members of the community in most developing countries, as well as being a recognized centre for public health programmes [21]. This study is therefore designed to evaluate awareness, knowledge, attitude and practice of ADR reporting among health workers and patients attending 10 selected PHCs in Ibadan, southwestern Nigeria.

\section{Methods}

Study site

Ibadan, the capital city of Oyo state in the southwest geopolitical zone of Nigeria comprised 11 Local Government Areas (LGAs) with 234 PHCs widely distributed across the nooks and crannies of the LGAs with different population size and coverage. Of the 11 LGAs, five LGAs were used for this study including Ibadan North (urban), Ibadan North East (urban), Ibadan South West (urban), Lagelu (semi-urban) and Akinyele (semi-urban) which were classified into urban and semi-urban LGAs based on their strategic and geographical locations within the city. There are about 114 PHCs spread across the five LGAs with different level of patients' patronage depending on their location within the LGA. Each LGA has a model PHC located either within or in close proximity to the LGA headquarters which is usually the prototype. A total of between 120 and 200 adult patients above 18 years were estimated to patronize the model PHC on a regular basis per month, while between 6 and 10 health workers were on full-time employment in each PHC. The 10 PHCs selected for this study comprised the model PHC for each LGA and another PHC chosen based on patients' patronage. The PHCs were IdiOgungun and Agbowo from Ibadan North LGA with a coverage of $4 \mathrm{~km}$ and $6 \mathrm{~km}$, respectively; Iwo Road and Alafara from Ibadan North East LGA with a coverage of $4 \mathrm{~km}$ and $9 \mathrm{~km}$, respectively; Bolumole $(3 \mathrm{~km})$ and Foko $(4 \mathrm{~km})$ from Ibadan South West LGA; Alegongo (5.6 $\mathrm{km})$ and Olorunda $(10 \mathrm{~km})$ from Lagelu LGA; Moniya and Sasa PHCs from Akinyele LGA with a coverage of 2 $\mathrm{km}$ and $6 \mathrm{~km}$, respectively. 


\section{Study design}

A questionnaire-guided cross-sectional survey among health workers and patients attending the selected PHCs in Ibadan, southwestern Nigeria between October and December 2018.

\section{Study population}

All the PHC workers on full-time employment as healthcare practitioner as well as adult patients attending the selected PHCs for medical care.

\section{Sampling techniques}

The 11 LGAs in Ibadan were stratified into urban and semi-urban LGAs, of this, five LGAs consisting of three urban and two semi-urban LGAs were selected using a systematic random sampling of every other LGA. Subsequently, $10 \mathrm{PHCs}$ were purposively selected from the five LGAs comprising the model PHC for each LGA and another PHC chosen based on relatively high patients' patronage. In each $\mathrm{PHC}$, total sampling of health workers on daily duty and consecutive sampling of patients receiving care in the $\mathrm{PHC}$ facility were done.

\section{Inclusion and exclusion criteria}

Full-time health workers involved in day-to-day treatment and care of patients at each PHC, as well as adult patients attending the $\mathrm{PHC}$ for health-related complaints and who gave consent for participation were enrolled. Workers in the PHCs who were solely employed for administrative duties, health workers on in-service or prequalification training as well as patients who declined participation were excluded.

\section{Sample size determination}

Sample size for the study was determined using Raosoft ${ }^{\circ}$ sample size calculator [22]. In each selected PHC, average of 40 adult patients regularly attend the facility per week, given an estimated population of 3200 patients from the $10 \mathrm{PHCs}$ for the 8 weeks study period (i.e. $40 \times 10 \times 8=3200$ ). Also, an average of eight health workers were on full-time employment in each PHC facility, given an estimated population of 80 health workers from the 10 PHCs (i.e. $10 \times 8=80$ ). Thus, computing the estimated population of the adult patients and health workers into the sample size calculator, at 95\% confidence level and 5\% margin of error gave a sample size of approximately 345 patients and 67 health workers. However, the inclusion of a $10 \%$ non-response rate gave a target sample size of approximately 380 for patients and 74 (rounded off to 80) for health workers, to guide participants' enrolment.

\section{Data collection instrument}

The questionnaires for the study were developed by the investigators following extensive review of relevant studies $[7-9,11,19]$, as well as utilizing previous practice experience. The semi-structured questionnaire for health workers consisted of four sections that explored demographic information, awareness and understanding of pharmacovigilance concept, as well as general knowledge about ADRs. Also, health workers' perceived attitude towards ADR reporting was evaluated using nine itemstatements with 5-points Likert scale response option, while ADR reporting practice among the health workers was also captured. The 5-points ordinal scale ranged from strongly agree (5) to strongly disagree (1) for positive statements (1-6), and a reversed ranked score for the negative statements (7-9). The questionnaire for the patients comprised three sections with question-items that captured socio-demographic characteristics, knowledge and awareness of pharmacovigilance and ADR reporting as well as ADR reporting practice (see Additional file 1).

\section{Pretest and validation of the instrument}

The questionnaires were assessed for content validity by two academic scholars who were expertise in the field of pharmacovigilance and ADRs. This is to ascertain the comprehensiveness of the item-statements in the questionnaires vis-à-vis the study objectives, as well as ensuring that there are no ambiguous questions or statements. Subsequently, pretest/face validity of the questionnaires was done among five PHC health workers and 15 patients recruited from one of the excluded PHCs, so as to ascertain the ease of comprehension of the question-items by would-be participants, as well as the appropriateness of the recruitment procedure. Feedback from the pretest and validity assessments led to minor modifications in the questionnaires such as the re-designing of some statements with a Yes/No response option as a ranked variable so as to ensure clarification of opinion.

\section{Data collection procedure}

Health workers were courteously approached when visited in their respective PHCs, largely during the scheduled duty shift period for individual worker and when there are less patients' workload. Writing material, specifically pen, was made available for those who may not have it handy at the time of filling the questionnaire. This approach was consistently applied throughout the period of the study, pointedly to ensure optimal cooperation and sustained interest of the health workers. Patients on the other hand, were enrolled for participation while waiting for their turn of treatment by the health workers. The informed consent form in the approved 
protocol, which captured the consent information including objectives and procedure of the study, risks and benefits of participation, as well as expected duration of involvement among others, was read and explained to individual participant prior to questionnaire administration. Subsequently, verbal informed consent was obtained from every participant to signify their intention for participation. The questionnaire for the health workers which took between 20 and 25 min to complete was self-administered by the workers and subsequently cross-checked for completeness before the disengagement of any participant. The interviewed-administered questionnaire to the patients which took about 25 to 30 min to complete, was done by the principal investigator. The patient's questionnaire and the informed consent form were translated into Yoruba, the local language for ease of understanding. Back-translation to English was later done to ensure response consistency. Participants' anonymity and confidentiality of responses were assured, while they were informed that participation in the study is entirely voluntary.

\section{Data analysis}

Data obtained were sorted, coded and entered into Microsoft Excel spreadsheet for ease of data management, and subsequently the computed data was exported into SPSS version 20.0 for analysis. Descriptive statistics including frequency and percentage was used to summarize the data. The sum total of score for the health workers in the knowledge and attitude domains was converted into percentage score, and subsequently developed into a binary category. In the knowledge domain, a total correct score $>80 \%$ (i.e. > 10 out of the 13 maximum obtainable score) was assigned as "adequate" general knowledge of ADRs and reporting, while a total score $\leq 80 \%$ was classified as "inadequate" knowledge. In the attitude domain, a total ranked score $>80 \%$ (i.e. $>36$ out of the 45 maximum points) signified "positive" attitude towards ADR reporting, while a total ranked score $\leq 80 \%$ was classified as "negative" attitude. The cut-off for the overall percent score in the knowledge and attitude domains was adapted from Bloom's cut-off point criteria, as well as other related studies [23, 24]. Pearson Chi-square or Fischer's Exact test as appropriate was used to evaluate association between healthcare workers' demographic variables and the overall knowledge and attitude scores. Association between patients' socio-demographic characteristics and ADR knowledge, as well as pharmacovigilance awareness and reporting of experienced ADRs was also done using Pearson Chi-square or Fischer's Exact test. The level of statistical significance was set at $p<0.05$.

\section{Results}

Demographic characteristics of health workers

All the 80 health workers enrolled within the study period responded to the questionnaire, given a response rate of $100 \%$. Seventy-four $(92.5 \%)$ were females and 6 (7.5\%) were males. The professional cadres of health workers who participated in the study included community health extension worker $(30 ; 37.5 \%)$, community health officer $(24 ; 30.0 \%)$, nurse $(20 ; 25.0 \%)$, health assistant $(4 ; 5.0 \%)$ and physician (2; 2.5\%). Majority, 53 (66.3\%) had practice experience within $\leq 1-5$ years and 13 (13.3\%) had > 5 years' experience.

\section{Knowledge and awareness of pharmacovigilance and ADRs among the health workers}

Fifty-eight $(72.5 \%)$ health workers had heard of pharmacovigilance, of this, most $(21 ; 36.2 \%)$ became aware through other healthcare professionals. Only 3 (5.2\%) understood the comprehensive definitions of pharmacovigilance. Forty-eight (60.0\%) believed that ADRs can only be experienced by a patient using orthodox medicines. Overall, $12(15.0 \%)$ of the health workers had total score $>80 \%$ suggesting "adequate" knowledge of ADRs (see Table 1).

\section{Health worker' perceived attitude towards ADR reporting} Seventy-nine $(98.8 \%)$ of the health workers expressed willingness to report all the ADRs encountered, 74 (92.5\%) believed that ADR reporting is part of their professional responsibilities as a healthcare professional, while all the health workers $(80 ; 100 \%)$ agreed that pharmacovigilance concept should be included as a component of training for PHC workers. Overall, 37 (46.2\%) had a total score $>80 \%$ indicating "positive" attitude towards ADR reporting (see Table 2).

\section{Adverse drug reaction reporting practice among the health workers}

Forty-seven (58.8\%) health workers had come across ADRs in their respective PHC. Measure(s) taken by those who had encountered ADRs were cited in combination to include referral to a secondary healthcare facility (50; 54.3\%), as well as treating the symptoms with another drug (30; 32.6\%) Table 3. Challenges preventing the health workers from reporting ADRs included unavailability of the reporting form $(40 ; 37.4 \%)$, insufficient clinical knowledge (35; 32.7\%), lack of experience in filling the ADR reporting form (10; 9.4\%), non-threatening nature of ADRs (10; 9.4\%), complicated nature of ADR reporting $(7 ; 6.5 \%)$, fear of liability $(4 ; 3.7 \%)$ and lack of time to report the ADRs $(1 ; 0.9 \%)$. Thirty $(37.5 \%)$ of the health workers had seen the ADR reporting form (Yellow form), but 17 (21.3\%) had the reporting form in their facility. A total of 11 (13.8\%) health workers had 
Table 1 Awareness and knowledge of pharmacovigilance and adverse drug reactions among the health workers

\begin{tabular}{|c|c|c|}
\hline Question/variable & Frequency & Percent \\
\hline \multicolumn{3}{|l|}{ Have you heard of pharmacovigilance? $(n=80)$} \\
\hline Yes & 58 & 72.5 \\
\hline No & 22 & 27.5 \\
\hline \multicolumn{3}{|l|}{ If yes, source of awareness of pharmacovigilance $(n=58)$} \\
\hline From other health professionals & 21 & 36.2 \\
\hline Through seminar and training & 18 & 31.0 \\
\hline Medical/Nursing school & 9 & 15.5 \\
\hline Advertisement & 9 & 15.5 \\
\hline Internet & 1 & 1.7 \\
\hline \multicolumn{3}{|l|}{ Wha What is your understanding of pharmacovigilance? $(n=58)$} \\
\hline The detection, assessment, and prevention of adverse effects and other drug-related problems & 24 & 41.4 \\
\hline The science and activities involved in reporting adverse drug reactions & 14 & 24.1 \\
\hline The process by which adverse drug reactions are monitored in a hospital & 10 & 17.2 \\
\hline A practice focused on medication and patient safety & 7 & 12.1 \\
\hline All of the above & 3 & 5.2 \\
\hline \multirow[t]{2}{*}{ 13-item knowledge questions in adverse drug reactions $(n=80)$} & \multicolumn{2}{|l|}{ Response, n (\%) } \\
\hline & YES & NO \\
\hline 1.An adverse drug reaction is a side effect that is commonly experienced when patient is using a drug & $53(66.3)$ & $27(33.7)^{\mathrm{a}}$ \\
\hline 2. An adverse drug reaction is an unintended effect of the drug during its administration & $65(81.2)^{a}$ & $15(18.8)$ \\
\hline 3. An adverse drug reaction is a predicted and expected reaction to a drug & $33(41.2)$ & $47(58.8)^{\mathrm{a}}$ \\
\hline 4. An adverse drug reaction is the same as a side effect & $22(27.5)$ & $58(72.5)^{\mathrm{a}}$ \\
\hline 5. An adverse reaction can only be experienced by a patient using orthodox medicines & $48(60.0)$ & $32(40.0)^{\mathrm{a}}$ \\
\hline 6. An adverse drug reaction can be experienced by a patient using herbal/traditional medicines & $45(56.2)^{a}$ & $35(43.8)$ \\
\hline 7. All adverse drug reactions are known before drug gets into the market for use & $21(26.2)$ & $59(73.8)^{a}$ \\
\hline 8. All adverse drug reactions experienced by a patient taking a drug should be reported and documented & $76(95.0)^{\mathrm{a}}$ & $4(5.0)$ \\
\hline 9. Only intolerable reactions to a drug should be reported & $25(31.2)$ & $55(68.8)^{a}$ \\
\hline 10. Adverse drug reaction may not be documented if the patient was appropriately counselled on such reaction & $25(31.2)$ & $55(68.8)^{a}$ \\
\hline 11. The best method of addressing adverse effect is to use or recommend another drug & $51(63.8)$ & $29(36.2)^{a}$ \\
\hline 12. There is no need to report an adverse drug reaction that is already documented in drug literature insert & 24(30.0) & $56(70.0)^{\mathrm{a}}$ \\
\hline 13. Reporting and documentation of adverse drug reaction is important & $76(95.0)^{a}$ & $4(5.0)$ \\
\hline Overall cut-off for knowledge score (\%) & Frequency (\%) & Remark \\
\hline Score $>80$ & $12(15.0)$ & Adequate \\
\hline Score $\leq 80$ & $68(85.0)$ & Inadequate \\
\hline
\end{tabular}

${ }^{a}$ Correct answer, maximum obtainable score $=13$, percent knowledge score $=$ Individual score divided by 13 multiply by 100

previous training in pharmacovigilance and ADR reporting, but 73 (91.3\%) expressed willingness to received training in pharmacovigilance and/or ADR reporting. Acquisition of more knowledge (56; 70.0\%) was largely mentioned as reason for the interest in pharmacovigilance/ADR training (see Table 3).

Table 4 shows the association between health workers' demographic characteristics and pharmacovigilance awareness, as well as overall ADR knowledge and attitude towards ADR reporting. Nurses (66.7\%) constituted those who significantly showed adequate general knowledge of ADRs compared to other professional cadres including physician (16.7\%), community health extension workers (16.7\%), community health officers $(0.0 \%)$ and health assistant $(0.0 \%)$ [Fisher's Exact Test $(\mathrm{FST})=21.44, p<0.001$ ]. Also, health workers with $\leq 1-5$ years practice experience in the PHC (68.8\%) significantly demonstrated positive attitude towards ADR reporting compared to those who had $>5$ years' experience (31.2\%) [Pearson Chi-square $\left(\mathrm{X}^{2}\right)=5.24, p=0.02$ ] see Table 4. There was a significant association among health workers with or without prior pharmacovigilance training and general knowledge of ADRs $\left(\mathrm{X}^{2}=4.57, p=\right.$ 
Table 2 Evaluation of health workers' perceived attitude towards adverse drug reaction reporting

\begin{tabular}{|c|c|c|c|}
\hline Attitudinal statements $(n=80)$ & $S A \& A$ & U & D \& SD \\
\hline 1.I would report all adverse drug reactions I encountered & $79(98.8)$ & $0(0.0)$ & $1(1.3)$ \\
\hline 2. ADR reporting is part of my responsibilities as a healthcare professional & $74(92.5)$ & $5(6.3)$ & $1(1.3)$ \\
\hline 3. Training of healthcare professionals can aid adverse drug reaction reporting & $77(96.2)$ & $0(0.0)$ & $3(3.8)$ \\
\hline $\begin{array}{l}\text { 4. I would be more likely to identify and report important adverse drug reactions } \\
\text { if I received training on pharmacovigilance }\end{array}$ & $73(91.3)$ & $7(8.8)$ & $0(0.0)$ \\
\hline 5. Reporting adverse drug reaction is part of my professional obligation & $71(88.8)$ & $7(8.8)$ & $2(2.5)$ \\
\hline 6. Pharmacovigilance concept should be included in the training of healthcare workers & $80(100.0)$ & $0(0.0)$ & $0(0.0)$ \\
\hline 7. I would likely report only life-threatening/severe adverse drug reactions & $44(55.0)$ & $3(3.8)$ & $33(41.3)$ \\
\hline 8. I would likely report only previously unknown adverse drug reactions & $23(28.8)$ & $7(8.8)$ & $50(62.5)$ \\
\hline 9. I do not think that tolerable, mild adverse drug reactions should be reported & $25(31.3)$ & $8(10.0)$ & $47(58.8)$ \\
\hline Overall cut-off for attitudinal score (\%) & & Frequency (\%) & Remark \\
\hline Score $>80$ & & $37(46.2)$ & Positive \\
\hline Score $\leq 80$ & & $43(53.8)$ & Negative \\
\hline
\end{tabular}

Items 1 to 6 are positive statements with rank score as strongly agree $(S A)=5$, agree $(A)=4$, undecided $(U)=3$, disagree $(D)=2$, strongly disagree $(S D)=1$, while items 7 to 9 are negative statements with reverse scoring as: $S A=1, A=2, U=3, D=4, S D=5$. Maximum obtainable score $=45$ points. Percentage score obtained $=$ individual score divided by 45 , multiply by 100

$0.03)$, as well as pharmacovigilance awareness (FET $=4.84$, $p=0.03)$. Health workers with no prior training $(66.7 \%)$ in pharmacovigilance constituted those who significantly showed adequate general knowledge of ADRs compared to those with training (33.3\%).

\section{Socio-demographic characteristics of patients}

A total of 360 out of the 380 eligible patients approached for participation in the study gave consent and completed the study, thus, a response rate of $94.7 \%$ was obtained among patients. Females constituted 311 (86.4\%) and males were 49 (13.6\%). Majority, $306(85.0 \%)$ were within the age range of $18-40$ years, while $54(15.0 \%)$ were above 40 years. Most $(187 ; 51.9 \%)$ of the patients were selfemployed, 96 (26.7\%) were civil/public servant and 77 (21.4\%) had no active employment. Patients who had no formal education or at most a primary education were 32 (8.9\%), secondary $(148 ; 41.1 \%)$ and post-secondary/tertiary education were 180 (50.0\%).

\section{Knowledge and awareness of pharmacovigilance and ADR reporting among patients}

Thirty-one (8.6\%) patients had heard of the term "pharmacovigilance", mostly (9; 29.0\%) through the social media platform. A total of 143 (39.7\%) patients correctly understood what can be regarded as an ADR. Seventeen (4.7\%) had prior knowledge of the short message service (SMS) alert short code for reporting experienced ADRs, with majority $(13 ; 76.5 \%)$ who got aware of the code through advertisement and online source (see Table 5).

Adverse drug reaction reporting practice among patients Eighty-nine $(24.7 \%)$ of the patients had experienced one form of $\mathrm{ADR}$ or the other. Informing a healthcare provider $(38 ; 38.8 \%)$ and stoppage of the drug (21; $21.4 \%)$ topped the list of actions taken by patients who had experienced ADRs. Direct reporting of experienced ADRs $(197 ; 54.2 \%)$ to healthcare professional was the most preferred method of ADR reporting among patients. Sixty-seven (18.6\%) of the patients reported the previously experienced ADRs. Suggested reasons for non-report of experienced ADRs included ignorance of the importance of ADR reporting $(111 ; 30.8 \%)$, as well as unserious nature of the ADRs $(105 ; 29.2 \%)$ see Table 6.

Table 7 shows the association between patients' socio-demographic characteristics and pharmacovigilance awareness, as well as ADR knowledge and reporting of previously experienced ADRs. Patients who had post-secondary/tertiary education were those with better pharmacovigilance awareness (90.3\%), ADR knowledge $(58.0 \%)$ and ADR reporting practice (56.7\%) compared to those with lower educational qualification $(p>0.05)$. Patients who were within the age of $18-40$ years $(71.6 \%)$ constituted those who largely reported the experienced ADRs compared to those above 40 years $(28.4 \%)\left[X^{2}=11.52, p=0.001\right]$ see Table 7 .

\section{Discussion}

In this study, close to three-quarters of the health workers were aware of pharmacovigilance, but approximately $5 \%$ correctly understand the comprehensive definitions of pharmacovigilance, while about one-sixth show adequate knowledge of ADRs. The proportion of health workers with inadequate level of ADR knowledge in our study is much lower than those reported in previous studies [25-27]. The disparity in ADR knowledge among participants from different studies may in part be linked to the possible variations in the criteria for 
Table 3 Adverse drug reaction reporting practice among the health workers

Variable Frequency (\%)

Ever encounter adverse drug reaction (ADR) at health facility $(n=80)$

Yes

47 (58.8)

No

Measure(s) taken in the case of encountered ADRs $(n=92)^{a}$

Refer to a secondary health facility

Treat symptoms with another drug

Provide counselling to patients

Stop the use of the drug

Ever come across ADR reporting form $(n=80)$

Yes

No

Is ADR reporting form available in your facility? $(n=80)$

Yes

No

Barrier(s) in obtaining the ADR reporting form $(n=17)$

No known source of obtaining the form

No proper distribution of form

Not the duty of primary healthcare

Who should report ADRs? $(n=91)^{\mathrm{a}}$

Any healthcare worker

Patients

Only senior healthcare worker

Ever received training on pharmacovigilance and/or ADR reporting? $(n=80)$

Yes

No

Opinion on willingness to receive training $(n=80)$

Yes

$\mathrm{No}$

Self-rating score on interest to undergo training in pharmacovigilance $(n=73)$

$<5$

$5-7$

$8(11.0)$

$8-10$

$65(89.0)$

Reasons for the interest to undergo pharmacovigilance training $(n=80)$

Acquire more knowledge on ADRs and reporting

Know more about the detection, assessment and prevention of ADRs

15 (18.7)

Patient care and safety

Easy access to ADR reports and early treatment of ADRs

More knowledge on ADRs, especially on how to fill the form

Regulatory bodies responsible for monitoring $\operatorname{ADRs}(n=138)^{\mathrm{a}}$

NAFDAC

46 (33.3)

$\mathrm{PCN}$

35 (25.4)

$\mathrm{FMOH}$

30 (21.7)

WHO

27 (19.6)

NAFDAC National Agency for Food and Drug Administration and Control, PCN Pharmacists Council of Nigeria, WHO World Health Organisation, FMOH Federal Ministry of Health, ADR Adverse Drug Reaction

Multiple response 
Table 4 Association between health workers' demographic characteristics and pharmacovigilance awareness, adverse drug reaction knowledge and attitude towards adverse drug reaction reporting

\begin{tabular}{|c|c|c|c|c|c|c|}
\hline \multirow[t]{2}{*}{ Variables } & \multicolumn{2}{|l|}{ ADR knowledge } & \multicolumn{2}{|c|}{ Attitude towards ADR reporting } & \multicolumn{2}{|c|}{ PV Awareness } \\
\hline & Adequate (Score > 80\%) & Inadequate (Score $\leq 80 \%$ ) & Positive (Score > 80\%) & Negative (Score $\leq 80 \%)$ & Yes & No \\
\hline \multicolumn{7}{|l|}{ Age (year) } \\
\hline $18-40$ & $9(75.0)$ & $49(72.1)$ & $26(70,3)$ & $32(74.4)$ & $39(67.2)$ & $19(86.4)$ \\
\hline \multirow[t]{2}{*}{$>40-60$} & $3(25.0)$ & 19 (27.9) & $11(29.7)$ & $11(25.6)$ & $19(32.8)$ & $3(13.6)$ \\
\hline & \multicolumn{2}{|l|}{$\mathrm{FET}=0.044 ; p=1.000$} & \multicolumn{2}{|l|}{$X^{2}=0.172 ; p=0.679$} & \multicolumn{2}{|c|}{$X^{2}=2.925 ; p 0.087$} \\
\hline \multicolumn{7}{|l|}{ Gender } \\
\hline Male & $1(8.3)$ & $5(7.4)$ & $2(5.4)$ & $4(9.3)$ & $3(5.2)$ & $3(13.6)$ \\
\hline \multirow[t]{2}{*}{ Female } & $11(91.7)$ & $63(92.6)$ & 35 (94.6) & $39(90.7)$ & $55(94.8)$ & $19(86.4)$ \\
\hline & \multicolumn{2}{|l|}{$\mathrm{FET}=0.014 ; p=1.000$} & \multicolumn{2}{|l|}{$\mathrm{FET}=0.435 ; p=0.681$} & \multicolumn{2}{|c|}{$\mathrm{FET}=1.647 ; p=0.338$} \\
\hline \multicolumn{7}{|l|}{ Marital status } \\
\hline Single & $6(50.0)$ & $15(22.1)$ & $6(16.2)$ & $15(34.9)$ & $17(29.3)$ & $4(18.2)$ \\
\hline \multirow[t]{2}{*}{ Married } & $6(50.0)$ & $53(77.9)$ & $31(83.8)$ & $28(65.1)$ & $41(70.7)$ & $18(81.8)$ \\
\hline & \multicolumn{2}{|l|}{$X^{2}=4.113 ; p=0.043^{*}$} & \multicolumn{2}{|l|}{$X^{2}=3.580 ; p=0.058$} & \multicolumn{2}{|c|}{$X^{2}=1.020 ; p=0.312$} \\
\hline \multicolumn{7}{|c|}{ Educational qualification } \\
\hline Primary & $0(0.0)$ & $1(1,5)$ & $0(0.0)$ & $1(2.3)$ & $0(0.0)$ & $1(4.5)$ \\
\hline Secondary & $0(0.0)$ & $2(2.9)$ & $0(0.0)$ & $2(4.7)$ & $1(1.7)$ & $1(4.5)$ \\
\hline \multirow[t]{2}{*}{ Tertiary } & $12(100.0)$ & 65 (95.6) & $37(100.0)$ & $40(93.0)$ & $57(98.3)$ & $20(90.9)$ \\
\hline & \multicolumn{2}{|l|}{$\mathrm{FET}=1.051 ; p=1.000$} & \multicolumn{2}{|l|}{$\mathrm{FET}=6.506 ; p=0.021^{*}$} & \multicolumn{2}{|c|}{$\mathrm{FET}=7.847 ; p=0.017^{*}$} \\
\hline \multicolumn{7}{|l|}{ Professional cadre } \\
\hline Nurse & $8(66.7)$ & $12(17.6)$ & $7(18.9)$ & $13(30.2)$ & $19(32.8)$ & $1(4.5)$ \\
\hline $\mathrm{CHO}$ & $0(0.0)$ & $24(36.3)$ & $15(40.5)$ & $9(20.9)$ & $15(25.9)$ & $9(40.9)$ \\
\hline CHEW & $2(16.7)$ & $28(41.2)$ & $12(32.4)$ & $18(41.9)$ & $20(35.4)$ & $10(45.5)$ \\
\hline Health assistant & $0(0.0)$ & $4(5,9)$ & $1(2.7)$ & $3(7.0)$ & $2(3.4)$ & $2(9.1)$ \\
\hline \multirow[t]{2}{*}{ Physician } & $2(16.7)$ & $0(0.0)$ & $2(5.4)$ & $0(0.0)$ & $2(3.4)$ & $0(0.0)$ \\
\hline & \multicolumn{2}{|l|}{$\mathrm{FET}=21.435 ; p<0.001^{*}$} & \multicolumn{2}{|l|}{$\mathrm{FET}=6.555 ; p=0.136$} & \multicolumn{2}{|c|}{$\mathrm{FET}=9.139 ; p=0.039^{*}$} \\
\hline Years of experience & in $\mathrm{PHC}$ & & & & & \\
\hline$\leq 1-5$ & $10(90.9)$ & $43(78.2)$ & $22(68.8)$ & $31(91.2)$ & $35(74.5)$ & $18(94.7)$ \\
\hline$>5$ & $1(9.1)$ & $12(21.8)$ & $10(31.2)$ & $3(8.8)$ & $12(25.5)$ & $1(5.3)$ \\
\hline & $\mathrm{FET}=0.939 ; p=0.678$ & & $X^{2}=5.242 ; p=0.022^{*}$ & & $\mathrm{FET}=3.51$ & $; p=0.088$ \\
\hline Previous training in & & & & & & \\
\hline Yes & $4(33.3)$ & $7(10.3)$ & $7(18.9)$ & $4(9.3)$ & $11(19.0)$ & $0(0.0)$ \\
\hline No & $8(66.7)$ & $61(89.7)$ & $30(81.1)$ & $39(90.7)$ & $47(81.0)$ & $22(100.0)$ \\
\hline & $x^{2}=4.565 ; p=0.033$ & & $x^{2}=1.551 ; p=0.213$ & & $\mathrm{FET}=4.83$ & $; p=0.030^{*}$ \\
\hline
\end{tabular}

FET Fischer's Exact Test, $X^{2}$ Pearson Chi-square, ${ }^{*}$ significant difference with Fischer's Exact or Pearson Chi-square test, $P V$ Pharmacovigilance, ADR Adverse drug reaction, $\mathrm{CHO}$ Community Health Officer, CHEW Community Health Extension Worker, PHC Primary Healthcare Centre. Level of statistical significance $p<0.05$

determining the cut-off point, as well as differences in the study settings. However, the low level of knowledge of ADRs and pharmacovigilance among the PHC health workers may perhaps be connected to the fact that a larger percentage of health personnel at the PHCs in Nigeria can be regarded as paramedical group of healthcare professionals who may not be statutorily mandated to possess a bachelor degree in their health-related disciplines, thus, there may be a greater likelihood that pharmacovigilance or subject related to ADRs might not have been included in their training curriculum. Worthy of note to mention is the fact that the two physicians who participated in this study were among those who had adequate knowledge of ADRs as well as pharmacovigilance awareness. Though, overall, nurses were found to have significantly adequate general knowledge of ADRs compared to other professional cadres. The low level of awareness of pharmacovigilance and inadequate knowledge of ADR reporting have been widely reported among healthcare professionals generally [26-29]. It is 
Table 5 Patients' knowledge and awareness of pharmacovigilance and adverse drug reaction reporting

\begin{tabular}{|c|c|}
\hline Variable & Frequency (\%) \\
\hline \multicolumn{2}{|l|}{ Ever heard of pharmacovigilance $(n=360)$} \\
\hline Yes & $31(8.6)$ \\
\hline No & $329(91.4)$ \\
\hline \multicolumn{2}{|l|}{$\begin{array}{l}\text { If yes, the source of pharmacovigilance } \\
\text { awareness }(n=31)\end{array}$} \\
\hline Social media platform & $9(29.0)$ \\
\hline Television & $5(16.1)$ \\
\hline Newspaper & $5(16.1)$ \\
\hline Radio & $3(9.7)$ \\
\hline Previous educational experience & $3(9.7)$ \\
\hline Internet & $3(9.7)$ \\
\hline A close healthcare professional & $3(9.7)$ \\
\hline \multicolumn{2}{|l|}{$\begin{array}{l}\text { What is your understanding of an adverse } \\
\text { drug reaction? }(n=360)\end{array}$} \\
\hline Any effect from a medication one is taken & $168(46.7)$ \\
\hline Unexpected reaction after taking a medication & $143(39.7)^{a}$ \\
\hline Expected reaction & $16(4.4)$ \\
\hline I do not know & $33(9.2)$ \\
\hline \multicolumn{2}{|l|}{ A serious adverse drug reaction means: $(n=363)^{b}$} \\
\hline A reaction that may lead to hospitalisation & $163(44.9)$ \\
\hline A reaction that is life-threatening & $133(36.6)$ \\
\hline A reaction that requires another drug treatment & $52(14.3)$ \\
\hline A reaction that resolves on its own & $14(3.9)$ \\
\hline I do not know & $1(0.3)$ \\
\hline \multicolumn{2}{|l|}{$\begin{array}{l}\text { Ever heard of SMS short code for reporting adverse } \\
\text { drug reactions }(n=360)\end{array}$} \\
\hline Yes & $17(4.7)$ \\
\hline No & $343(95.3)$ \\
\hline \multicolumn{2}{|l|}{$\begin{array}{l}\text { If yes, source of awareness of the SMS alert short } \\
\text { code }(n=17)\end{array}$} \\
\hline Advertisement and online sources & $13(76.5)$ \\
\hline Newspaper articles & $3(17.6)$ \\
\hline Friends & $1(5.9)$ \\
\hline
\end{tabular}

$n$ number, SMS Short message service

${ }^{\mathrm{a} C}$ Correct answer, ${ }^{\mathrm{b}}$ multiple response

also noted that about one-seventh of the health workers had prior pharmacovigilance or ADR-related training. Lack of training opportunities in pharmacovigilance has been reported in previous studies in Nigeria [8,30], consequently most healthcare professionals had not received training on ADR detection and reporting [8, 31, 32]. However, our study reveals that those without prior training in pharmacovigilance significantly constituted those with adequate general knowledge of ADRs and pharmacovigilance awareness compared to those with training. Even though the reason for this perceived disparity may not be clearly ascertained from our study. However, it may be necessary to consider the fact that for any formal training geared towards transfer and acquisition of knowledge such as pharmacovigilance or ADR related training, the appropriateness of the content, the quality of resource materials as well as the suitability of training delivery mode to facilitate learning and the expertise of resource person constitute important factors that may largely dictate the extent to which participants can grasp and internalize the content. Thus, in conducting a pharmacovigilance or ADR-related training, it may be essential to ensure that all the aforementioned attributes are featured in the training concept/idea in order to enhance knowledge acquisition by participants. Interestingly, over $90 \%$ of the health workers signify interest to undergo training in pharmacovigilance and/or ADR reporting, with approximately $90 \%$ who gave a self-rated score of between 8 and 10 as evidence to show for their level of interest in the training. Reasons cited largely include acquisition of more knowledge, especially in ADR detection, assessment, reporting and prevention. The overwhelming interest of health workers to receive training in pharmacovigilance needs to be further pursued by relevant authorities, perhaps through initiation of a mandatory continuing education programme on pharmacovigilance and/or ADR reporting for the PHC health workers across the country. Providing continuous educational activities, as well as cooperation among relevant stakeholders to disseminate information has been identified as effective intervention tool in improving spontaneous reporting [16, 33-35]. Of note is the fact that all the health workers supported the incorporation of pharmacovigilance concept into their training curriculum.

Overall, less than half of the health workers demonstrate positive attitude towards ADR reporting. Even though, healthcare providers play a significant role in ensuring a robust pharmacovigilance system, the rate of spontaneous reporting of ADRs by healthcare professionals in many countries is extremely low (6-10\%), which may in part be due to the fact that spontaneous $\mathrm{ADR}$ reporting is not a mandatory requirement in most countries $[11,12]$. However, in our study, perusing the response of health workers to specific attitude statement, it is observed that a substantial proportion expressed an encouraging positive attitude towards ADR reporting, although, the perceived positive attitude may not be a direct reflection of what may happen in clinical practice. Nevertheless, if this promising positive attitude towards ADR reporting among the PHC health workers can be further reinforced and pursued, perhaps through consistent and continuous training of the health workers, there may be improvement in ADR reporting rate. More especially considering the fact that the PHC health workers are the healthcare professionals who are closest to the 
Table 6 Adverse drug reaction reporting practice among the patients

\begin{tabular}{|c|c|c|}
\hline Variable & Frequency & Percent \\
\hline \multicolumn{3}{|l|}{ Have you ever experienced an adverse drug reaction? $(n=360)$} \\
\hline Yes & 89 & 24.7 \\
\hline No & 271 & 75.3 \\
\hline \multicolumn{3}{|l|}{ Action taken in the case of adverse effect/reaction $(n=98)^{* *}$} \\
\hline Informed a healthcare professional & 38 & 38.8 \\
\hline Stopped the drug(s) & 21 & 21.4 \\
\hline Did nothing because the reaction was tolerable & 17 & 17.3 \\
\hline Did nothing because the reaction resolved on its own & 11 & 11.2 \\
\hline Used another drug to treat symptoms of reaction & 7 & 7.1 \\
\hline Switched to herbal/traditional medicines & 3 & 3.1 \\
\hline Switched to another drug & 1 & 1.1 \\
\hline \multicolumn{3}{|l|}{ Sources of obtaining information about adverse drug reactions $(n=531)^{* *}$} \\
\hline Drug leaflet & 172 & 32.4 \\
\hline Pharmacist & 134 & 25.2 \\
\hline Physician & 82 & 15.4 \\
\hline Internet & 81 & 15.3 \\
\hline Nurse & 58 & 10.9 \\
\hline Relative/Friend & 4 & 0.7 \\
\hline \multicolumn{3}{|l|}{$\begin{array}{l}\text { Suggested reasons why patients do not report experienced adverse } \\
\text { drug reactions }(n=360)\end{array}$} \\
\hline Do not know the importance of reporting adverse drug reactions & 111 & 30.8 \\
\hline Adverse reaction may not be very serious & 105 & 29.2 \\
\hline Do not know how to report such reactions & 86 & 23.9 \\
\hline Not sure if adverse reaction is related to the medication(s) used & 53 & 14.7 \\
\hline Adverse effect/reactions resolved on its own & 5 & 1.7 \\
\hline \multicolumn{3}{|l|}{ Preferred methods of adverse drug reaction reporting $(n=363)^{* *}$} \\
\hline Reporting directly to healthcare professional & 197 & 54.2 \\
\hline Phone call or text message & 108 & 29.7 \\
\hline Online application designed for adverse drug reaction reporting & 26 & 7.2 \\
\hline Filling a reporting form & 20 & 5,5 \\
\hline Filling an online reporting form & 12 & 3.3 \\
\hline
\end{tabular}

people of the grassroot [21] who may largely be exposed or constitute a more vulnerable population to the eventual consequence(s) of ADRs. Overall, the health workers who are younger in the practice $(\leq 1-5$ years) significantly demonstrate positive attitude towards ADR reporting compared to those with greater than 5 years practice experience. Incorporation of ADRs and pharmacovigilance themes into the educational institutions and curricula where health disciplines are taught may therefore be an important use of formal educational channels, to actively incorporate $\mathrm{ADR} / \mathrm{pharmacovigilance} \mathrm{concept}$ into the future healthcare professional career, with the potential of strongly influencing perception and attitude towards ADR reporting [36].
In this study, nearly $60 \%$ of the health workers had encountered an ADR case(s) in their practice site, and most of those who had come across ADRs took measures such as referral of the case to a secondary healthcare facility, while some engaged in treating the ADR symptom(s) with another drug. These actions taken by the health workers can be regarded as a mix of good and poor practice with respect to ADRs. In Nigeria and perhaps some other resource-poor countries, healthcare practitioners at the PHCs are usually expected to handle minor ailments, as well as involve in follow-up of patients with uncomplicated chronic disease conditions, thus, referral of ADR case(s) to a secondary healthcare facility may constitute a good practice by the health 
Table 7 Association of patients' socio-characteristics with pharmacovigilance awareness, knowledge of adverse drug reaction and reporting of experienced reactions

\begin{tabular}{|c|c|c|c|c|c|c|}
\hline \multirow[t]{2}{*}{ Variables } & \multicolumn{2}{|c|}{ Knowledge of ADR definition } & \multicolumn{2}{|c|}{ PV Awareness } & \multicolumn{2}{|c|}{ Reporting of experienced ADRs } \\
\hline & Adequate & Inadequate & Yes & No & Yes & No \\
\hline \multicolumn{7}{|l|}{ Age (year) } \\
\hline $18-40$ & $118(82.5)$ & $188(86.6)$ & $25(80.6)$ & $281(85.4)$ & $48(71.6)$ & $258(88.1)$ \\
\hline \multirow[t]{2}{*}{41 and above } & $25(17.5)$ & $29(13.4)$ & $6(19.4)$ & $48(14.6)$ & $19(28.4)$ & $35(11.9)$ \\
\hline & \multicolumn{2}{|c|}{$X^{2}=1.147 ; p=0.284$} & \multicolumn{2}{|c|}{$X^{2}=0.505 ; p=0.478$} & \multicolumn{2}{|c|}{$X^{2}=11.521 ; p=0.001^{*}$} \\
\hline \multicolumn{7}{|l|}{ Gender } \\
\hline Male & $19(13.3)$ & $30(13.8)$ & $4(12.9)$ & $45(13.7)$ & $8(11.9)$ & $41(14.0)$ \\
\hline \multirow[t]{2}{*}{ Female } & $124(86.7)$ & 187(86.2) & $27(87.1)$ & $284(86.3)$ & $59(88.1)$ & $252(86.0)$ \\
\hline & \multicolumn{2}{|c|}{$X^{2}=0.021 ; p=0.884$} & \multicolumn{2}{|c|}{$\mathrm{FET}=0.014 ; p=1.000$} & \multicolumn{2}{|c|}{$X^{2}=0.195 ; p=0.658$} \\
\hline \multicolumn{7}{|l|}{ Marital status } \\
\hline Single & $55(38.5)$ & $60(27.6)$ & $10(32.3)$ & $105(31.9)$ & $13(19.4)$ & $102(34.8)$ \\
\hline Married & $84(58.7)$ & $152(70.0)$ & $20(64.5)$ & $216(65.7)$ & $52(77.6)$ & $184(62.8)$ \\
\hline \multirow[t]{2}{*}{ Widowed/Divorced } & $4(2.8)$ & $5(2.3)$ & $1(3.2)$ & $8(2.4)$ & $2(3.0)$ & $7(2.4)$ \\
\hline & \multicolumn{2}{|c|}{$\mathrm{FET}=4.973 ; p=0.083$} & \multicolumn{2}{|c|}{$\mathrm{FET}=0.478 ; p=0.801$} & \multicolumn{2}{|c|}{$\mathrm{FET}=6.343 ; p=0.037^{*}$} \\
\hline \multicolumn{7}{|l|}{ Occupation } \\
\hline Civil/public servant & $41(28.7)$ & $55(25.3)$ & $13(41.9)$ & $83(25.2)$ & $21(31.3)$ & $75(25.6)$ \\
\hline Self-employed & $71(49.7)$ & $116(53.5)$ & $11(35.5)$ & $176(53.5)$ & $30(44.8)$ & $157(53.6)$ \\
\hline \multirow[t]{2}{*}{ No active employment } & $31(21.7)$ & $46(21.2)$ & $7(22.6)$ & $70(21.3)$ & $16(23.9)$ & $61(20.8)$ \\
\hline & \multicolumn{2}{|c|}{$X^{2}=0.607 ; p=0.738$} & \multicolumn{2}{|c|}{$X^{2}=4.757 ; p=0.093$} & \multicolumn{2}{|c|}{$X^{2}=1.728 ; p=0.421$} \\
\hline \multicolumn{7}{|l|}{ Educational qualification } \\
\hline No formal education/Primary & $6(4.2)$ & $26(12.0)$ & $1(3.2)$ & $31(9.4)$ & $4(6.0)$ & $28(9.6)$ \\
\hline Secondary & $54(37.8)$ & $94(43.3)$ & $2(6.5)$ & $146(44.4)$ & $25(37.3)$ & $123(42.0)$ \\
\hline \multirow[t]{2}{*}{ Post-secondary/Tertiary } & $83(58.0)$ & $97(44.5)$ & $28(90.3)$ & $152(46.2)$ & $39(56.7)$ & $142(48.5)$ \\
\hline & \multicolumn{2}{|c|}{$X^{2}=9.594 ; p=0.008^{*}$} & \multicolumn{2}{|c|}{$\mathrm{FET}=23.619 ; p<0.001^{*}$} & \multicolumn{2}{|c|}{$X^{2}=1.820 ; p=0.402$} \\
\hline
\end{tabular}

FET Fischer's Exact Test, $X^{2}$ Pearson Chi-square, ${ }^{*}$ significant difference with Fischer's Exact or Pearson Chi-square test, PV Pharmacovigilance, ADR Adverse drug reaction. Level of statistical significance $p<0.05$

workers that needs to be encouraged. However, recommending another drug to treat an ADR symptom(s) may not be considered as a rational or good practice, since the act may possibly results into further negative consequences, especially when the cause of the initial reaction has not been fully explored.

In this study, a larger proportion of health workers expressed willingness in reporting all the ADRs encountered, however, a number of challenges preventing ADR reporting were cited, which includes unavailability of reporting form in the $\mathrm{PHC}$, as well as insufficient clinical knowledge and experience in filling the ADR reporting form among others. Nonavailability of ADR reporting form and non-existence of a formal reporting system are consistent with previous studies $[8,27,31,37]$, thus, an issue that needs to be proactively addressed by concerned stakeholders, most especially the National Pharmacovigilance Centre (NPC) in the case of Nigeria. Ensuring availability and proper distribution of ADR form across the healthcare facilities from time to time, as well as embarking on continuous enlightenment and education of PHC health workers may be some of the measures to explore in order to ensure improvement in ADR reporting rate. Studies have indicated the availability of ADR reporting form (i.e. Yellow form), as well as a user-friendly reporting form as impetus for improving ADR reporting practice [35, 36].

Our study also reveals that less than $10 \%$ of the patients had heard of pharmacovigilance, while nearly $5 \%$ were aware of the short message service (SMS) alert short code for reporting ADRs but more than one-third display a good understanding of what can be regarded as an ADR. Previous studies in developed and developing countries have also reported low level of awareness of pharmacovigilance activities $[6,38]$. Of note is the fact that most patients who heard of pharmacovigilance became aware through the social media platform, as well as news media, largely television and radio. News and social media platforms have been recognized as potential sources of gathering data on patients' experience with medicines, though there are concerns about its effectiveness in supplementing routine 
pharmacovigilance activities [18, 19, 39]. Nevertheless, online sources and other contemporary technology, if properly utilized may be used to sensitize and create awareness about pharmacovigilance generally and ADR reporting in particular, with subsequent improvement in reporting practice.

It is however noted that nearly one-fifth of the patients reported the previously experienced ADRs. Ignorance of the importance of ADR reporting as well as unserious nature of the ADRs were topmost of the suggested reasons for non-report of experienced ADRs. Patients within the age of $18-40$ years were significantly better in reporting experienced ADRs compared to those above 40 years. This perhaps suggests the need to further geared efforts towards continuous public education and enlightenment campaigns on the importance of prompt and timely report of experienced ADRs to healthcare professionals or used the SMS alert short code to report the experienced ADRs to the National Pharmacovigilance Centre.

Approximately one-quarter of the patients had experienced one form of ADR or the other, topmost on the list of measures taken by patients who experienced an ADR includes informing a healthcare professional, as well as stoppage of the drug(s). These actions taken by the patients may be considered as the first necessary steps whenever one experiences an ADR, before the proper investigation(s) to establish the link between the reaction and the suspect drug. Interestingly, more than half of the patients wish to report ADRs directly to a healthcare professional, while close to one-third prefer phone call or text message to a designated number for ADR reporting. This perhaps underscores the need to explore combination of approach including social media platform in ensuring sensitization and dissemination of information about early detection and reporting of ADRs.

Despite the useful information from this study, the following limitations are necessary for consideration. First, the cross-sectional nature of the study with only a snapshot of participants in the selected PHCs may lead to the possibility of selection bias especially among the patients. Also, the self-reported nature of the study may be associated with some inherent limitations such as participants who may either over- or under-report the information provided, while the possibility of recall bias may not be totally excluded. Nevertheless, self-report measure especially using a non-judgmental or non-threatening questioning approach has been described as a reliable tool to elicit a somewhat accurate information from the respondents, as it may make respondents to feel more comfortable in telling the truth $[40,41]$. Another limitation of our study may be related to the relatively small number of PHCs covered in the selected LGAs which may affect the widespread generalisation of study findings to the entire PHCs in the region, though the sample size used for our study is representative of the health workers and patients in the studied PHCs. Moreover, the choice of using the model PHC in each LGA which is the prototype, as well as the design of the item-statements in the questionnaire to cover fundamental aspects of ADRs/pharmacovigilance concept may partly allow for a comprehensive exploration of health workers and patients on the subject area, hence, a useful strength for our study. Nevertheless, future study may need to put into consideration the identified gaps in order to ensure a far-reaching conclusion.

\section{Conclusions}

It can be concluded that health workers in the selected PHCs were largely aware of pharmacovigilance but show low level of knowledge about ADRs and pharmacovigilance concept, with moderately positive attitude towards ADR reporting. Patients on the other hand demonstrate low level of awareness of pharmacovigilance and ADR reporting, with less than one-fifth who reported the previously experienced ADRs. This perhaps underscores a need for regular mandatory education and training on ADRs/pharmacovigilance concept among the PHC health workers, while continuous public enlightenment and awareness campaigns on spontaneous reporting of ADRs is advocated in order to enhance reporting rate.

\section{Supplementary information}

Supplementary information accompanies this paper at https://doi.org/10. 1186/s12913-019-4775-9.

Additional file 1. Questionnaires for the study.

\section{Abbreviations}

ADR: Adverse drug reaction; CHEW: Community health extension worker; $\mathrm{CHO}$ : Community health officer; EC: Ethics committee; FMOH: Federal Ministry of Health; FST: Fischer's exact test; LG: Local government area; NAFDAC: National Agency for Food and Drug, Administration and Control; NPC: National Pharmacovigilance Centre; PCN: Pharmacists Council of Nigeria; PHC: Primary health care; PV: Pharmacovigilance; SMS: Short message service; SPSS: Statistical package for social sciences; UI: University of Ibadan; WHO: World Health Organisation

\section{Acknowledgements \\ The authors acknowledge all the health workers and patients who volunteered to be part of the study.}

\section{Authors' contributions}

RA designed the study, conduct the statistical analysis, developed the manuscript and completed the final write up of the manuscript. TIO was involved in the design of the study, collection of data and draft of the manuscript. Both authors read, revised and approved the paper before its final submission.

\section{Authors' information}

Rasaq Adisa is a Ph.D holder, Senior Lecturer and the current Head of Department, Clinical Pharmacy and Pharmacy Administration, Faculty of Pharmacy, University of Ibadan, Ibadan, Nigeria.

Tomilayo Inioluwa Omitogun is an internee pharmacist at the University College Hospital, Ibadan, and a graduate project student in the Department of Clinical Pharmacy and Pharmacy Administration, Faculty of Pharmacy, University of Ibadan, Ibadan, Nigeria. 


\section{Funding}

No fund or support was received in carrying out this study.

\section{Availability of data and materials}

The datasets used and/or analysed during the current study are available from the corresponding author on reasonable request.

\section{Ethics approval and consent to participate}

Ethics approval for the study was obtained from the University of Ibadan/ University College Hospital Ethics Review Committee with approval number UI/EC/18/0429. Permission was also obtained from the Head of respective primary healthcare centres. Verbal informed consent in accordance with the approved study protocol by the Ethics committee, was obtained from individual participant after explaining the objectives and procedure of the study to participant individually. The consent information as contained in the informed consent form was read and explained to individual participant prior to questionnaire administration. Verbal informed consent was deemed appropriate for our study being a questionnaire-based survey with questions carefully designed without infringement on participants' privacy. Also, the questionnaire and informed consent form for the patient was duly translated into the local language of the patients for proper comprehension. Only the consented participants within the study period were enrolled,

\section{Consent for publication}

Not applicable.

\section{Competing interests}

The authors declare that they have no competing interests.

Received: 30 July 2019 Accepted: 22 November 2019

\section{Published online: 03 December 2019}

\section{References}

1. Aronson JK. Adverse drug reactions- no farewell to harms. Br J Clin Pharmacol. 2007;63(2):131-5.

2. Pirmohammed M, James S, Meakin S, Green C, Park BK. Adverse drug reactions as a cause of admission to the hospital: prospective analysis of 18820 patients. Br Med J. 2004;329:15-9.

3. Rodriguez-Monguiro R, Otero MJ, Rovira J. Assessing the economic impact of adverse drug effects. Pharmacoeconomics. 2003:21:623-50.

4. Pal SN, Duncombe C, Falzon D, Olsson S. WHO strategy for collecting safety data in public health programmes: complementing spontaneous reporting systems. Drug Saf. 2013:36:75-81.

5. Almandil NB. Healthcare professionals' awareness and knowledge of adverse drug reactions and pharmacovigilance. Saud Med J. 2016;37(12):1359-64.

6. Aziz Z, Siang TC, Badarudin NS. Reporting of adverse drug reactions: predictors of under-reporting in Malaysia. Pharmacoepidemiol Drug Saf. 2007; 16:223-8.

7. Hazell L, Shakir SA. Under-reporting of adverse drug reactions: a systematic review. Drug Saf. 2006;29:385-96.

8. Oshikoya KA, Awobusuyi J. Perceptions of doctors to adverse drug reaction reporting in a teaching hospital in Lagos, Nigeria. BMC Pharmacol Toxicol. 2009;9(1):14

9. Perez-Garcia M, Figuerias A. The lack of knowledge of voluntary reporting system of adverse drug reactions as a major cause of under-reporting: direct survey among health professionals. Pharmacoepidemiol Drug Saf. 2011;20:1295-302

10. Okechukwu R, Odinduka S, Ele G, Okonta M. Awareness, attitude and practice of pharmacovigilance among health care professionals in Nigeria: survey in a teaching hospital. Int J Hosp Res. 2013;2(3):99-108.

11. British Medical Association Board of Sciences: Reporting adverse drug reactions- a guide for healthcare professionals. 2006. Accessed 15 May 2019 from http://www.isopouline.org/wp-content/uploads/2015/01/BMAreport.pdf

12. Balidemaj F. Adverse drug reactions problems with spontaneous reporting systems and communicating information to providers to improve reporting rate globally. Working paper from the University of Oxford2013. Accessed 15 May 2019 from http://universum-ks.org/wp-content/uploads/2014/09/ Balideng-003-2013pdf.

13. Molokhia M, Tanna S, Bell D. Improving reporting of ADRs: a systematic review. Clin Epidemiol. 2009;1:175-92.
14. Nisa ZU, Zafar A, Sher F. Assessment of knowledge, attitude and practice of adverse drug reaction reporting among healthcare professionals in secondary and tertiary hospitals in the capital of Pakistan. Saud Pharm J. 2018;26:453-61.

15. Hughes ML, Whittlesea CM, Luscombe DK. Review of national spontaneous reporting schemes: strengths and weaknesses. Adverse Drug React Toxicol Rev. 2002;21(4):231-41.

16. Olsson S, Pal SN, Stergachis A, Couper M. Pharmacovigilance activities in 55 low- and middle-income countries: a questionnaire-based analysis. Drug Saf. 2010;33(8):689-703.

17. Adams SA. Using patient-reported experiences for pharmacovigilance? Stud Health Technol Inform. 2013;194:63-8.

18. Lexchin J. Is there still a role for spontaneous reporting of adverse drug reactions? Can Med Assoc J. 2006;174(2):191-7.

19. World Health Organization. Consumer reporting of Adverse Drug Reactions, WHO Drug Information 2000. Accessed 15 May 2019 from www.who.int/ medicines/policy/consumerreporting.

20. Rolfes $L$, van der Linden $L$, van Hunsel $F$. The documentation of clinical information of adverse drug reaction: a paired comparison of duplicate reports of patients and healthcare professionals. Pharmacoepidemiol Drug Saf. 2016;25(3):418.

21. Adeyemo DO. Local government and health care delivery in Nigeria: a case study. J Human Ecol. 2005;18(2):149-60.

22. Raosoft Sample Size Calculator. Accessed 20 Dec 2018 from http://www raosoft.com/samplesize.html.

23. Abdullahi A, Hassan A, Kadarman N, Saleh A, Baraya YS, Lua PL. Food safety knowledge, attitude and practice toward compliance with abattoir laws among the abattoir workers in Malaysia. Int J Gen Med. 2016;9:79-87.

24. Nahida A. Knowledge, attitude and practice of denque fever prevention among the people in male, Maldives, Published Masters' Dissertation. Thailand: Chulalongkorn University; 2007.

25. Seid MA, Kasahun AE, Mante BM, Gebremaham SN. Healthcare professional knowledge, attitude and practice towards adverse drug reaction reporting at the health center level in Ethiopia. Int J Clin Pharm. 2018:40:895-902.

26. Mulatu WN, Worku A. Assessment of knowledge attitude and practice of health professionals toward adverse drug reaction reporting and factors associated with reporting. Aust J Pharm. 2014;2:4.

27. Carandang RR, Cao K, Jose NB, Almonte FD, Tinio RM. Knowledge and attitudes on adverse drug reaction reporting of selected hospital-based health practitioners in Manila, Phillipines. Sch Acad J Pharm. 2015:4:301-7.

28. Su C, Ji H, Su Y. Hospital pharmacists' knowledge and opinions regarding adverse drug reporting in North China. Pharmacoepidemiol Drug Saf. 2010; 19:217-22.

29. Katakhaye VM, Kadhe NG, John J, Pawar SR. Knowledge, attitude and practice of pharmacovigilance among medical professionals at a tertiary care hospital in Mumbai, Maharashtra, India. Int J Res Med Sci. 2016;5:156-61.

30. Osakwe A, Oreagba T, Adewumi AJ, Adekoya A, Fajolu I. Impact of training on Nigerian healthcare professionals' knowledge and practice of pharmacovigilance. Int J Risk Saf Med. 2013:25(4):219-27.

31. Okezie EO, Fawole O. Adverse drug reaction reporting by physicians in Ibadan, Nigeria. Pharmacoepidemiol Drug Saf. 2008;17(5):517-22.

32. Oreagba I, Ogunleye O, Olayemi S. Knowledge, attitudes and practices among community pharmacists in Lagos, Nigeria. Pharmacoepidemiol Drug Saf. 2011;20(1):30-5

33. Aagaard L, Nelsen LH, Hansen EH. Consumer reporting of ADRs: a retrospective analysis of the Danish ADR data base from 2004 to 2006. Drug Saf. 2009;32(11):1067-74.

34. Jadeja M, Inglefield P. An evaluation of the EU wide social media campaign to raise awareness of national spontaneous adverse drug reaction reporting system 2017. Accessed 15 May 2019 from http://www.scopejoitaction.eu/_ assets/file/2017-01-17-SCOPE-ADR-social-media-campaign-evaluation-FINALmitul-jadeja.pdf.

35. Gonzalez-Gonzalez C, Lopez-Gonzalec E, Hendeiro MT, Figuerras A. Strategies to improve adverse drug reaction reporting: a critical and systematic review. Drug Saf. 2013;36(5):317-28

36. Elshafie S, Roberti AM, Zaghlgul I. Pharmacovigilance in developing countries (part II): a path forward. Int J Clin Pharm. 2018;40:764-8.

37. Amit D, Rataboli PV. Adverse drug reaction notification drop box. An easy way to report adverse drug reactions. Br J Clin Pharmacol. 2008;66(5):723-4.

38. Robertson J, Newby DA. Low awareness of adverse drug reaction reporting systems: a consumer-survey. Med J Austr. 2013;199:684-6. 
39. Kuthya S, Kalaiselvan V, Kaur J, Singh GN. Mobile application: an approach to enhance easy adverse drug reactions reporting in India. Health Technol. 2016;6(2):157-8.

40. MacLaughlin EJ, Raehl CL, Treadway AK, Sterling TL, Zoller DP, Bond CA. Assessing medication adherence in the elderly: which tools to use in clinical practice? Drug Aging. 2005;22:231-55.

41. Gehi AK, Ali S, Na B, Whooley MA. Self-reported medication adherence and cardiovascular events in patients with stable coronary heart disease: the heart and soul study. Arch Intern Med. 2007;167:1798-803.

\section{Publisher's Note}

Springer Nature remains neutral with regard to jurisdictional claims in published maps and institutional affiliations.

Ready to submit your research? Choose BMC and benefit from:

- fast, convenient online submission

- thorough peer review by experienced researchers in your field

- rapid publication on acceptance

- support for research data, including large and complex data types

- gold Open Access which fosters wider collaboration and increased citations

- maximum visibility for your research: over $100 \mathrm{M}$ website views per year

At $\mathrm{BMC}$, research is always in progress.

Learn more biomedcentral.com/submissions 